\title{
Automatic Sweethearts for Transhumanists
}

\section{Michael Hauskeller}

In this chapter I will primarily address three questions. First, if we assume, as several futurists profess to believe (Kurzweil 1999, 142-148; Levy 2008, 22; Pew Research Center 2014, 19), that within a few decades we will be able to build robots that do all the things that we would normally expect a real human lover and sexual companion to do, and that do them just as well, will they then also be, as lovers and companions, as satisfying as a real person would - or will we have reason to think or feel that something is amiss, that they are, in some way, not as good? To answer this question, I shall assume that those robots will not be real persons, by which I mean that although they may give the impression of being a person, they are in fact not persons. A person, as I am using the term here, is a being that is both self-aware and self-concerned. A being is self-aware if there is (to use Nagel's felicitous phrase) something it is like to be that being, and it is selfconcerned if it matters to it what happens in the world, and especially what happens to it. A real person is a being that does not merely appear to be self-aware and self-concerned, by showing the kind of behaviour that we have learned to expect from a self-aware and self-concerned being, but one that really is self-aware and self-concerned. A being that only behaves as if it were a person, without being one, I shall call a pseudo-person.

However, in initially making the assumption that those robotic sexual companions of the future will not be real persons in the specified sense, I am not committing myself to the view that it will never be possible for us to create artificial persons. While I do not think that this is very likely, I am happy to concede that, since we do not know what exactly gives rise to self-awareness and self-concern, we can at this stage not entirely rule out the possibility that one day we will be able to create machines that are real persons. If that happened, then those robots would either be designed to reliably perform certain tasks, say to love, cherish, obey, and sexually gratify us, or they would not. If they were not designed to reliably perform such tasks and instead were free to make up their own mind about what they want to do and what not (to the same extent that we are), then we would have little if any reason to create them in the first place (except perhaps to see whether it is possible to do so), simply because they would not in any relevant way differ from human persons (which are, after all, much cheaper to produce). It is therefore most likely that if we figure out how to create selfaware and self-concerned robots we will also seek to make sure that they always do what we want them to do and nothing else, or, preferably (to avoid certain ethical issues, which will be briefly addressed later on), that they always want to do what we want them to do. This leads me to my 
second question: would an artificial person (a real one, not a pseudo-person) who has been designed and programed to reliably give us exactly what we expect a human lover to give us, namely both the actions and the accompanying emotions, thoughts and attitudes, be, as a lover and companion, as satisfying as a person is (be they human or human-made) who gives us all this without having been designed and programed to do so?

However, although what we experience as satisfying and what not to some extent depends on what we are (namely as human beings with certain instincts and needs that we all share), it also depends on who we are (namely as individuals with certain personalities, attitudes and world-views that may well differ from those of others). For this reason, what satisfies me may not satisfy you, and vice versa. So the two questions raised above - namely whether pseudo-persons would, as lovers and companions, be as satisfying as real persons, and whether real persons who are free (in the sense of not being programed to obey inbuilt commands) would be as satisfying as real or pseudo persons who are not free - should not be understood as questions about actual levels of satisfaction, but rather as questions about possible grounds for satisfaction and dissatisfaction. We will see, though, that those grounds can appeal differently to different people, such that the very same feature that makes an object or relationship appear more satisfactory to some people can make it appear less satisfactory to others. Thus what we may regard as a vital defect in pseudo persons, one that would make them less satisfactory to us than real persons and thus give us grounds to reject them as adequate lovers and companions, we may also see as an asset, something that actually makes them superior to real persons. This consideration gives rise to my third and last question: on what grounds can sexual companion robots be regarded as being not only just as good as human lovers, but in fact as better, i.e. as more satisfactory.

\section{Love and Sex with Robotic Pseudo-Persons}

In a footnote to his book The Meaning of Truth (1909, 189) William James briefly considers whether an artificial lover could pragmatically ever be as satisfying as a real human one. He imagines this artificial lover, which he calls "automatic sweetheart", as a "soulless body which should be absolutely indistinguishable from a spiritually animated maiden, laughing, talking, blushing, nursing us, and performing all feminine offices as tactfully and sweetly as if a soul were in her." By 'soul' James of course means subjectivity or a first-person perspective: an inner life that accompanies and motivates those loving and caring actions that he describes and discreetly alludes to as "feminine offices". The automatic sweetheart would do all those things that we expect them to do exactly like they would if they really felt what their actions suggest they feel, i.e., if they really 
loved us and really cared for us. Except that they do not. Ex hypothesi, an automatic sweetheart does not feel or think anything. They are not real persons, but merely pseudo-persons. As mindless service providers they would simply perform certain functions, and perform them perfectly. Would that be enough? Would that give us all we need and want? James is certain that it would not, for the following reason: "Because, framed as we are, our egoism craves above all things inward sympathy and recognition, love and admiration. The outward treatment is valued mainly as an expression, as a manifestation of the accompanying consciousness believed in." So what James is saying here is that what we value in others (due to the way we are "framed", i.e. to our human nature), or at any rate what we value in those with whom we have an intimate relationship, is not primarily the fact that they behave or treat us in a certain, seemingly loving way, but that they do so precisely because they love us.

However, it is difficult to see what this love (the subjective feelings and thoughts of which the behaviour is supposedly a mere expression) should consist in, if not in a certain kind of loving behaviour. If my lover treats me badly and does not show any concern for my well-being (by, say, looking after me when I'm sick, or by taking care of my needs), then it does not seem to make much sense to insist that they, despite all, do love us. And vice versa, if their behaviour towards us is unfailingly caring and loving and respectful of our needs, then we would not really know what to make of the claim that they do not really love us at all, but only appear to do so. We would expect that the alleged lack of love would show in some way, and if it never does, then their love is as real as it can possibly be. The philosophical behaviourist Edgar Arthur Singer raised this objection against James in his book Mind as Behavior (1924, 9). While a "soulless sweetheart" is indeed unsatisfactory, he argued, their soullessness does not consist in the absence of feeling, but in their behaviour, in what they do and do not do:

no one would regard a soulless sweetheart as a full equivalent for a soulful one, as these words 'soulless' and 'soulful' are ordinarily used. But just there is the point: how are they ordinarily used? If I imagine myself come to believe that my mistress, with all her loveliness, is really without soul, I cannot think what I should mean by this if it be not that I fear her future conduct will not bear out my expectations regarding her. Some trait or gesture, a mere tightening of the lips, hardening of the eye, stifling of a yawn, one of those things we say are rather felt than seen, would have raised in my mind the suspicion that she might not to my fuller experience of her remain indistinguishable from a spiritually minded maiden.

On this view, we do not, in fact, infer the presence of (a certain kind of) mind from a person's behaviour. Rather, their behaviour is their mind (Singer 1924, 10). This is exactly the position that David Levy adopts in his Love \& Sex with Robots $(2008,11)$ : "There are those who doubt that we 
can reasonably ascribe feelings to robots, but if a robot behaves as though it has feelings, can we reasonably argue that it does not? If a robot's artificial emotions prompt it to say things such as 'I love you,' surely we should be willing to accept these statements at face value, provided that the robot's other behaviour patterns back them up."

Yet the reason why it may not make much sense to doubt the love of somebody who unfailingly behaves lovingly towards us is that we would be hard-pressed to come up with a plausible explanation for why they would do such a thing. By far the best explanation for their loving behaviour is that they really love us. This does not show that there is no clear distinction between real love and loving behaviour (or more precisely a behaviour that is, qua behaviour, indistinguishable from a behaviour that is inspired by real love). How we feel is one thing, and how we behave is, despite obvious connections between the two, quite another. While we usually, though by no means necessarily, express our feelings and attitudes through our behaviour, so that our behaviour is normally a reliable indicator of how we feel, we can also hide our 'soul' and act as if we felt very differently. Moreover, we know from self-experience that we are beings whose actions are more than just movements in physical space. Instead, they are always interwoven with, and expressive of, self-awareness and self-concern. We are real persons, and we know that we are. We also know that whatever a person does, there is some connection to the subjective side of their existence. A robot, however, is a machine primarily designed to behave in a certain way and, depending on its purpose, perhaps also to make us believe that there is something it is like to be that robot. Those companies that today are already producing and marketing social robots (including sexual companion robots) do their best to blur the difference between real persons and pseudo persons and encourage us to get emotionally involved with their products. This strategy seems to be paying off. As Matthias Scheutz has pointed out, we are hardwired to ascribe intentions to entities that are mobile and exhibit some degree of autonomy, and thus easily fall prey to the "suggestive force of apparent autonomous behaviour" (Scheutz 2012, 213), and it is likely that the more the machines we build and use resemble real persons in their behaviour the harder it will become to escape that suggestive force. Yet while it is quite possible that we are easily fooled, that our natural constitution as human (or more generally animal) beings makes it rather difficult for us not to ascribe self-awareness to a machine that behaves exactly as we would expect it to if it were really self-aware, as long as we have an alternative explanation for why it behaves that way (namely that it has been designed and programed to do so) we have no good reason to believe that its actions are expressive of anything at all. Even a perfect simulacrum is still a simulacrum, and our natural tendency to take the simulacrum for the real thing does nothing to change that. 
Now, if James was right to surmise that what we want from a lover is that they really love us and not simply behave as if they loved us (while in fact not feeling anything at all), then a robot pseudoperson can never be as satisfactory as a human lover (at least not if we know that they are not human and have reason to believe or suspect that their apparent love is merely a clever simulation). Yet this also means that they can only be seen as satisfactory replacements for a human lover if all we care about, all we value, is what the other does, while not caring at all about how they feel or whether they feel anything at all. Human interaction is thus conceptually reduced to the behavioural aspect of it. True companionship where one person relates to another through, or by means of, their interactions, is then no longer regarded as an end (because it is thought to be either unachievable or undesirable, or both). Instead, the means now is (understood to be) the end.

The attentive reader will have noticed that so far I have made no attempt to distinguish between love and sex, and I suspect that while many would agree that a robotic pseudo-person can never give us what we expect from somebody we love (namely that they love us back or at the very least that they are aware and appreciative of our love for them), the claim that such robots would be perfectly satisfactory as partners in a purely sexual relationship will be generally considered to be much more plausible. Yet the reason why I have avoided drawing a clear line between love and sex is not that I fail to acknowledge the difference. It is quite obvious to me that we can love someone without having sex with them, and have sex with them without loving them. So I am not conflating love with sex, nor do I think there is anything morally wrong with having casual sex, or sex without love. However, it seems to me that even what appears to be a purely sexual relationship between human partners is very often, and certainly can be, more than just sex (if we take 'sex' to be a purely physical event). For one thing, it always, by necessity, involves an intimate encounter with another human being, a sharing of an experience. It is not merely the coming-together of two bodies that interact with each other. Rather, it is the interaction of two (or more) embodied persons. For another, when we have sex with another person, we are not, at least not normally, simply using the other person to, as it were, scratch a sexual itch. Sex is also about, and fuelled by, desire, and the knowledge or belief that this desire is reciprocated. We want to be or feel desired. We desire the other who desires us desiring them. Our lust and the pleasure we experience is at least partly a response to the lust and pleasure we incite in the other and to the lust and pleasure they desire to incite in us. Sex, or perhaps we should better say good sex - the kind that D.H. Lawrence used to call "tender-hearted fucking" (cf. Hauskeller 2014, 53-63) - is a practice of desire-sharing, a particular form of companionship and communion. In order to be fully satisfied with a robotic pseudo-person designed for sexual pleasure (who is by definition incapable of feeling any desire) we would have to attach no value to the inter-personal aspects of sex, i.e., to those aspects of sex that can make it such a rich and exhilarating experience in the first place. This becomes quite 
evident when David Levy $(2012,227)$ declares that the "prime purpose of a sexbot is to assist the user in achieving orgasm, without the necessity of having another human being present." The human that is not present, and whose absence is supposedly fully compensated by the presence of the robot, is here seen as having the same function as the robot, namely to "assist the user in achieving orgasm". Not only does this view reduce the sexual act to what it often leads up to (as if nothing else mattered; the process itself discounted), it also assumes that to achieve full sexual satisfaction we do not need anybody else. All we need is someone or something (it doesn't matter which) that pushes the right buttons, that scratches what needs scratching and tickles what needs tickling. This someone could also be us. In other words, the other who is no longer a partner, but merely an 'assistant', is nothing more than a rather overdeveloped masturbation device. You don't necessarily need a robot for that, and you certainly don't need a person. If sex is in any case nothing but masturbation (and at best mutual masturbation), then there is no reason to think that a pseudoperson, designed with sufficient technological sophistication, could not meet the job requirements just as well as a real person. But if sex is in fact more than that, or at least can be more than that, a communion of some sort, then sex with a pseudo-person can, just like masturbation, never be as satisfactory or fulfilling as sex with a real person. ${ }^{1}$

\section{Love and Sex with Robotic Persons}

But what if we eventually managed to build robots that are real persons? Robots that can desire us as much as we can desire them, robots that can really love us back and feel what we feel. Would they then be just as good as a human lover? I am reasonably sure that for many they would, provided they are, in all relevant respects, just like us (except perhaps better looking and more skilled in the art of pleasuring the flesh). The fact that they would be human-made rather than human-born should not make a difference, although for some it might. Yet that would simply be a personal preference. Some might prefer synthetic lovers, others natural ones, just like some men prefer blondes and others brunettes. This does not say anything about their general preferability as sexual or romantic partners. However, that future social robots will in all relevant respects be like us is even more unlikely than that they will be persons, for the simple reason that they will in any case be made for a purpose, while humans generally are not (at least not yet). In order for them to exist we will have to make them, and we are not going to do that without a good reason for it, and that means, without there being a need or demand for them. In other words, there has to be a market for them. So why would anyone want a robot lover? Why would anyone be willing to pay for them? Whitby (2012) lists several plausible motivations. Obviously sexual companion robots might appeal to those who have trouble finding a human lover. Not everyone has the appearance or social skills 
that would make them attractive as a sexual partner to others, and even if they do find someone, those they can get may not be the ones they would have chosen if they had a choice. A sexual robot would allow those who are less sexually attractive not only to find a partner, but also to find a very attractive one. Others may simply like the idea of having sex with a machine (or in this case an artificial person). Possible reasons for this I have discussed elsewhere (Hauskeller 2015). Some people may feel drawn to the undemanding nature of robots that are designed to please us, and some may look forward to being able to do with their robotic partner whatever they want to without being restricted in any way by morality or by what their partner happens to like and dislike. But whatever the motivation, in order to give those people what they want we can perhaps allow robots to be persons in the specified sense, but what we cannot allow is that they are free to act in a way that runs counter to the wishes of their buyers. If they think and feel, that's fine, perhaps even desirable, but they must love us when we want them to love us and have sex with us when we want them to have sex with us. Their freedom needs to be restricted. Otherwise we would have no reason to create (and, perhaps more importantly, buy) them in the first place.

The required restriction of freedom can be achieved in two different ways. One option is to decide and decree that what the robot wants is of no significance and then to install a mechanism that prevents it from doing anything other than what we want it to do, either by programing it in such a way that it cannot disobey our commands (always assuming that this is possible, which it may well not be), or by creating a moral and legal framework that effectively leaves the robot no choice but to do our bidding (for fear of the repercussions that disobedience would incur). Both would amount to institutionally sanctioned slavery and might appeal to those who find rape (by which I here mean making someone have sex with you who does not want to have sex with you) more gratifying than consensual sex. The other, seemingly more morally palatable option is to design and program robots in such a way that they never want to do anything other than what the buyer wants them to do. The first option has been suggested by Joanna Bryson (2010), and the second by Steve Peterson (2012).

According to Bryson, robots should be slaves. Not only would there be nothing morally wrong with keeping them as slaves, but also would it be morally wrong not to do so. It would be wrong to grant them any kind of moral status because doing so would draw time and energy, as well as care and emotional investment, away from those who deserve it, namely human persons. Ascriptions of personhood are a valuable resource with which we should not be too generous. And it would not be morally wrong to refuse robots moral consideration and keep them as slaves because we have created them specifically for that purpose, that is, to serve our needs and wants. For this reason we should not have to treat them as persons or grant them any rights that we usually grant persons. As far as I can see, this claim is not based on the assumption that humanoid robots will not be real 
persons in the sense specified above, but only pseudo-persons. The term 'person', for Bryson, seems to signify a being that deserves moral recognition. Personhood is here not a quality that an entity can possess, but something that is or is not owed to it. The term is thus purely normative and does not seem to have any descriptive dimension. Curiously, there is no suggestion in Bryson's paper that whether those robots are real persons or pseudo-persons in a descriptive sense might in any way be relevant for the question how we should regard and treat them. Rather, what settles the question for her is the fact that we have designed and produced them and therefore own them. There would be no robots without us, Bryson argues, they owe their existence solely to the fact that we needed and wanted somebody to perform a certain role. Since that is what they are here for, they are not entitled to demand or expect anything else from us. It does not really matter whether they are persons or pseudo-persons; what matters is that they are in either case still machines, made by us. And if we are, regardless, still afraid that an ethical issue might arise from enslaving them, we could just design them in such a way that they don't mind their lack of freedom. It is entirely up to us: "Remember, robots are wholly owned and designed by us. We determine their goals and desires. A robot cannot be frustrated unless it is given goals that cannot be met, and it cannot mind being frustrated unless we program it to perceive frustration as distressing, rather than as an indication of a planning puzzle." (Bryson 2010, 72) However, we, as their makers, have no direct moral obligation to them to spare them distress. At least that is how I understand Bryson's argument. If that is a fair reading, then I don't think the argument is very persuasive. The fact that an entity would not exist if we hadn't wanted it to exist, and to exist for a certain purpose, does not strip that entity of all moral standing. The same argument can, after all, also be made (and actually has been made) about the animals we breed for food and as pets. It may even be said about our own children. Yet since we don't usually accept this kind of reasoning (i.e., that what we create we own, and what we own has no rights), creating self-aware and self-concerned robot servants who do not want to serve us but have to do so anyway is not really an option.

To forestall such ethical concerns, Steve Peterson (2012) has suggested that we should design and program our robot servants in such a way that they want to serve us, or more generally that they want to do what we want them to do. So if nothing made them happier than to fulfil our every wish, then we would neither harm nor wrong them in any way by allowing them to do so. Nor would we wrong them by making it, right from the start, impossible for them to want anything else. If their wishes were always aligned with ours, then we would, Peterson argues, in fact not be treating them as mere means, because whatever we asked them to do would, per definition, benefit them just as much as us. It would not only serve our ends, but also their ends. Peterson does not think that we would thereby condemn them to a meaningless life. He rejects the idea that there are higher and lower pleasures, or pursuits that are more worth-pursuing than others: instead, any pursuit must be 
regarded as worth pursuing as long as someone happens to get their kicks from it. Even our noblest pursuits are, after all, pretty meaningless in the grand scheme of things. And we do not usually think that the life of an animal (who is not capable of higher pursuits) is not worth living. If we did, we should, or would, not allow them to exist in the first place.

While this is not the place to discuss in detail the ethics of creating artificial persons to serve us, a few remarks may be in order. If we accepted Peterson's argument, then we would have to suppose that for example the life of a Sisyphus who were designed and programed to find nothing more pleasurable than pushing a rock up a hill for his entire life is just as meaningful and fulfilling as the life of, say, a rescue worker who helps saving other people's lives. More importantly, we would also have to suppose that there is nothing wrong, nothing morally objectionable, with deliberately creating such a Sisyphus for our own ends (perhaps because we find it immensely amusing to see him pushing that bloody stone up the hill day after day, or, if we are more philosophically-minded, to serve as a living reminder of the utter meaninglessness of all existence). Even though he may then not be doing anything that he does not want to do, we would still treat him merely as a means to our ends. To treat somebody as an end in itself does not merely mean that we let them do what they want to do, but also to allow them to want things that we don't. It is about allowing someone to find their own ends without us making the decision for them. This is why it would also be wrong to breed or genetically engineer human persons who desire nothing more than to serve us, which following Peterson's logic would be morally unobjectionable, too.

Now imagine we had the means to create robotic or human persons whose only desire was to fulfil our sexual desires, whatever they may be. Custom-made models could be ordered online, fitted not only with specific bodily features, but also with particular preferential attitudes. People would get what they want, and what they want is someone who wants what they want them to want, for instance "an airhead silicon bimboid obsessed with serving them sexually, or perhaps a skinnier anal-addicted Ukrainian model", or, for the more outlandish tastes, "babies for rape" or "snuff robots which scream and bleed realistically when their arms are sawn off' (Treanor 2015). All that would presumably be fine, ethically speaking (following Peterson), as long as those treated that way do not mind because it is what they themselves want anyway. Except it is not all right. It is demeaning, and the fact that we would have designed them to find pleasure in a demeaning life, makes it not less, but even more demeaning. ${ }^{2}$

Although the question I intended to address in this paper is not whether it can be morally acceptable to have a sexual relationship with a robot, but whether such a relationship could ever be as satisfying as a sexual relationship with a human lover, the two questions are not as unconnected as it may seem. If that relationship does not agree with our ethical commitments, then we won't be able 
to regard and experience it as fully satisfying. That, of course, depends on our ethical commitments, whether we have any in the first place, and if yes, which. However, whether or not we have such commitments, the ethical features of a situation can still function as objective grounds for satisfaction and dissatisfaction in the sense that if a relationship is, to put it mildly, morally dubious, then, whether or not we are satisfied with it, it still remains the case that we should not be satisfied with it.

However, while most people will probably agree that the life of a person programed to meet every and any sexual demand that we may have is indeed demeaning, this does not, or at least not so obviously, seem to be the case when a person is not designed for sex, but for love. What if I just want somebody who loves me the way I am, someone who is good to me and there for me and will not tire of me and will not leave me because they find somebody who they think is more lovable? Surely there is nothing demeaning about loving a particular person and loving them reliably. So if it were possible to create such a person, and I ordered and purchased him or her, it does not seem that that person's life would be bad or meaningless because of it. (I am, after all, not such a bad guy and deserve to be loved by someone.) We may of course still take issue with the fact that they have been designed to love us and hence have no choice in the matter, but it is difficult to argue that point and I will not try to do this here. ${ }^{3}$ So let us assume for now that creating persons programed to love us is morally unobjectionable (as unobjectionable as, say, creating a person programed with a burning desire to cure cancer). Would they then be as satisfying as a real (unprogramed) human person who just happens to love us?

They might not, even if we have no ethical concerns about it. That is because, as Dylan Evans has pointed out, we do not only desire to be loved, but we usually also have the second-order desire to be loved freely, i.e. by choice. "Although people typically want commitment and fidelity from their partners, they want these things to be the fruit of an ongoing choice, rather than inflexible and unreflexive behavior patterns." (Evans 2010, 81) We do not want people to love us because they have been hypnotised or enchanted (like Shakespeare's fairy queen Titania who is made to fall in love with a donkey-headed weaver). And programing is, after all, just a different type of enchantment. Of course we do not usually mind that those who love us 'cannot help themselves', that their commitment to us is deeper and more unshakable than what a deliberate choice could provide (which can at any moment be revoked). Yet we do want the other to love us for what and who we are and not no matter what we are. We want it to be their choice and not ours (or, for that matter, a third party's). This entails a certain contingency, and with it the possibility of loss. Even though we fear that possibility, we are unlikely to accord much value to a love that is ours whatever 
we do. We will probably tire of it very quickly. If that is correct, then an automatic sweetheart, even if they are real persons, will not be as satisfying as a human person who (really) loves us.

\section{Love and Sex with Robotic Post-Persons}

On the other hand, the prospect of having somebody that loves us reliably, someone who we know won't leave us no matter what, will certainly have a strong appeal to many. So there is indeed, as Evans puts it, a dilemma at the heart of the human-robot relationship: "We want contradictory things: a romantic partner who is both free and who will never leave us." (Evans 2010, 84) And if we cannot have both, then, depending on what we value most, we may well prefer the reliable artefact to the never completely reliable human. What is more, we might not even see this as a huge loss, or for that matter any loss, in the first place. We can, after all, always convince ourselves that nothing is really missing, that the robot gives us all that we can possibly get, or at any rate all that is worth having. The pseudo-person can be designed to appear and act like a real person, and if we cannot detect a difference and trust that "soul" is ultimately nothing but behaviour, then the pseudoperson will be just as good as a person. And if the robot is a real person, but not free to do anything but what we want them to do, then they can still appear free, and we can then, following the same reasoning, tell ourselves that they are free. It is easy to lie to ourselves if it gets us what we want: "we are alone and imagine ourselves together" (Turkle 2011, 226).

Yet we may not even have to fool ourselves. Even if we are perfectly aware that the other that serves us as a pseudo-partner for sex and love does not really feel anything at all, or that if they do, they have been programmed to do so and hence have no real choice in the matter, we may actually prefer them that way. Being alone can be our preferred option. To engage with someone, a real human person, is, after all, always risky. Not only do we never quite know what we will get or whether we will actually get what it says on the tin, we are also constantly expected to take into account and sympathetically respond to their needs and desires. Real people are demanding and do not always perform the way we want them to. The great advantage of robots is that they do:

Sexbots will never have headaches, fatigue, impotence, premature ejaculation, pubic lice, disinterest, menstrual blood, jock strap itch, yeast infections, genital warts, AIDS/HIV, herpes, silly expectations, or inhibiting phobias. Sexbots will never stalk us, rape us, diss us on their blog, weep when we dump them, or tell their friends we were boring in bed. Sexbots will always climax when we climax if we press that little button on their butt. (Pellissier 2009) 
The author of this (by no means tongue-in-cheek) eulogy on sex robots, Hank Pellissier, used to be the managing director of the Institute for Ethics and Emerging Technologies (IEET), which has established itself as one of the two main transhumanist associations and think tanks (the other being Humanity Plus). The IEET's mission is to promote "ideas about how technological progress can increase freedom, happiness, and human flourishing" (http://www.ieet.org/index.php/IEET/about). Humanity Plus has a similar agenda: to elevate the human condition by expanding human capabilities and making us "better than well". Their motto is "Don't limit your challenges. Challenge your limits." (http://humanityplus.org/about/) The suggestion that we can actually benefit from replacing human partners with robots must be understood in this context. Robots for sex and love constitute an important step towards the realisation of a shared transhumanist agenda, which rests firmly on two ideological pillars: libertarianism and hedonism. From a transhumanist perspective, our goal should be to get the maximum amount of pleasure out of everything we do which according to Nick Bostrom is, after all, nothing less than the "birth right of every creature" (Bostrom 2010, 6) - and to become as free/ independent/ autonomous as possible. These two goals are connected, of course. Our limitations are thought to be a principal source of displeasure and unhappiness. Consequently, once we are free of all limitations there will be nothing left to be unhappy about. Pellissier himself makes this connection explicit in a recent article, published on IEET's website. After examining the various kinds of "suffering caused by our enslavement to our outdated neurochemistry", he concludes that as "Free-will Transhumans, who decided 100\% of the time what we wanted to think, feel and do", we would not only be "immensely more powerful", but also, precisely for this reason, much happier (Pellissier 2015).

Now the problem with entering into relationships with other people is that, although they certainly can be a source of pleasure, more often than not they stand in the way of it. Moreover, even when they give us pleasure and happiness, this pleasure and happiness is always tainted and diminished by the fact that we need them to get it. Loving a human being and having sex with them might be pleasurable, but this pleasure can easily be taken away from us. From a transhumanist perspective, the fact that we depend on other people for sex and love is almost as annoying as the fact that we have to die or more generally the fact that we cannot do anything and everything that we want to do and not be anything and everything that we want to be. This (and not merely the fact that they might know better how to please and pleasure us) is the main reason why Levy thinks that sex and love robots are not only not deficient in any way, but actually better companions and lovers than a human could ever be. ${ }^{4}$ Consider again the statement quoted earlier: "The prime purpose of a sexbot is to assist the user in achieving orgasm, without the necessity of having another human being present." (Levy 2012, 227) To have another human present is currently still a necessity, which is exactly what makes it problematic. Any necessity is bad because, by definition, it curbs our 
freedom. Necessities prevent us from being self-sufficient and truly autonomous. Sex robots are good not only because they are much more fun to be with, but also, even primarily, because they make us more independent. We should re-evaluate our attitude towards sex accordingly. "Are Sexbots icky? Are humans pathetic if we don't just mate with each other? Truth is, we're already mostly 'solo' when it comes to orgasms. 'Masturbation,' noted Hungarian psychiatrist Thomas Szasz, 'is the primary sexual activity... in the 19th century it was a disease, in the 20th it's a cure."' (Pellissier 2009)

A cure for what, though? Pellissier does not answer the question directly, but it is clear from the context that what this masturbation-by-sexbot is thought to be a cure for is the disease of other human beings (or the disease of our dependence on them). This gives a whole new meaning to Sartre's famous dictum that "hell is other people". The underlying logic is worrying. It hints at a paradox at the heart of the transhumanist agenda. If the goal is to increase my autonomy, and if other people by virtue of having desires and needs of their own that differ from mine necessarily impose limits on my autonomy, then in order to increase my own autonomy I need to find ways to decrease the autonomy of others, or, if that is not feasible, to create a world for myself that allows me to do what I want to without requiring the collaboration of others. As long as I have to interact with real others, as long as we share a world, our autonomy will always be severely restricted. Therefore the only possible way for me to become completely independent is by cutting all ties to other persons, by making my own world, uninhabited by any real persons except myself. Perfect autonomy (and thus supposedly perfect happiness) requires complete detachment. Robotic pseudopersons or persons can then be understood as an enhanced version of other people. They are in fact, in more than one sense, post-persons.

\section{Bibliography}

Bryson, Joanna J. (2010): "Robots Should Be Slaves", in Close Engagements with Artificial Companions. Key social, psychological, ethical and design issues, ed. Yorick Wilks, Amsterdam/ Philadelphia: John Benjamins Publishing Company, 63-74.

Danaher, John (2016): "Robotic Rape and Robotic Child Sex Abuse: Should they by criminalised?", Criminal Law and Philosophy (DOI: 10.1007/s11572-014-9362-x, forthcoming, 2016).

Evans, Dylan (2010): "Wanting the Impossible. The dilemma at the heart of intimate human-robot relationships", in Close Engagements with Artificial Companions. Key social, psychological, ethical 
and design issues, ed. Yorick Wilks, Amsterdam/ Philadelphia: John Benjamins Publishing Company, 75-74.

Hauskeller, Michael (2014): Sex and the Posthuman Condition, Basingstoke: Palgrave Macmillan.

Hauskeller, Michael (2015): “Messy Bodies, or Why We Love Machines”, in Making Humans, ed. Alexander Darius Ornella, Freeland: Inter-Disciplinary Press.

Hauskeller, Michael (2016): "Is It Desirable to Be Able to Do the Undesirable", Cambridge Quarterly of Healthcare Ethics (forthcoming).

James, William (1909): The Meaning of Truth. A Sequel to 'Pragmatism', New York, Bombay and Calcutta: Longmans, Green and Co.

Kurzweil, Ray (1999): The Age of Spiritual Machines, New York: Viking 1999.

Levy, David (2008): Love \& Sex with Robots. The Evolution of Human-Robot Relationships, London: Duckworth Overlook.

Levy, David (2012): “The Ethics of Robot Prostitutes", in Robot Ethics, eds. Lin et al, 223-231.

Lin, Patrick, Keith Abney, and George A. Bekey (2012): Robot Ethics. The Ethical and Social Implications of Robotics, Cambridge, MA: MIT Press.

Mikes, George (1986): How to Be a Brit, Harmondsworth: Penguin.

Pellissier, Hank (2009): "Sexbots will give us longevity orgasm”, Humanity plus Magazine, 11 December 2009, http://hplusmagazine.com/2009/12/11/sexbots-will-give-us-longevity-orgasm/

Pellissier, Hank (2015): Free Will Does Not Exist - Should it be a Transhumanist Enhancement?”, http://ieet.org/index.php/IEET/more/pellissier20150727

Petersen, Steve (2012): “Designing People to Serve”, in Robot Ethics, eds. Lin et al, 283-298.

Pew Research Center (2014): “AI, Robotics, and the Future of Jobs", http://www.pewinternet.org/2014/08/06/future-of-jobs/

Scheutz, Matthias (2012): “The Inherent Dangers of Unidirectional Emotional Bonds between Humans and Social Robots", in Robot Ethics, eds. Lin et al, 205-221.

Singer, Edgar Arthur (1924): Mind as Behavior and Studies in Empirical Idealism, Columbus, OH: R.G. Adams and Co. 
Treanor, Paul (2015): “Bimboid utopia: what do men want?",

https://politicalaspects.wordpress.com/2015/02/06/bimboid-utopia-what-do-men-want/

Turkle, Sherry (2011): Alone Together. Why We Expect More from Technology and Less from Each

Other, New York: Basic Books.

Whitby, Blay (2012): “Do You Want a Robot Lover? The Ethics of Caring Technologies”, in Robot

Ethics, eds. Lin et al, 234-248.

\footnotetext{
${ }^{1}$ George Mikes, in his humorous 1946 classic How to Be an Alien, quipped that "continental people have sex life; the English have hot-water bottles" (Mikes 1986, 25). Sex robots are something like the hot-water bottles of the future.

${ }^{2}$ John Danaher has recently (2016) discussed how it may be considered morally wrong (and hence apt for criminalisation) to engage in sexual activities with robots deliberately designed to cater to "paedophilic tastes and rape fantasies". Danaher assumes that those robots will be pseudo-persons, which makes it more difficult to establish any wrongdoing. However, he argues (although rather tentatively) that such activities may reasonably be regarded as harmful to the moral character of those who engage in them. Although I think more needs to be said about what that means exactly, the point is well-taken. Perhaps the supposed harm to moral character can be best understood in relation to the self-demeaning nature of the activity. And if the robot subjected to these activities is a person, then what is happening is demeaning for both.

${ }^{3}$ I have tried to make that argument in Hauskeller 2016.

${ }^{4}$ Evans (2010) fittingly calls this the "greater satisfaction thesis".
} 